\title{
Glycaemic indices of commonly consumed Sri Lankan foods and variation in blood glucose
}

\author{
Ekanayake $\mathbf{S}^{1}$ \\ Journal of the Ceylon College of Physicians, 2019, 50, 77-83
}

\section{Summary}

The paper presents data on glycaemic indices (GI), glycaemic load (GL) and some factors that contributed to the variations observed in $\mathrm{Gl}$ of commonly consumed Sri Lankan foods. New improved raw (kekulu) rice if eaten with minimum of accompaniments gives rise to a higher $\mathrm{Gl}$ in contrast to, consuming as a mixed meal with many curries which elicits a low Gl. However, parboiled rice elicits a low $\mathrm{Gl}$ and traditional rice elicits a low or medium $\mathrm{Gl}$ even with minimum of accompaniments. Bread gives rise to a lower GI (medium) if accompanied by curries. String hoppers irrespective of flour variety elicit a high $\mathrm{Gl}$ even when given with many accompaniments. Pittu produces higher $\mathrm{Gl}$ with wheat or rice flour but elicits lower $\mathrm{GI}$ when produced with kurakkan flour. In contrast roti elicits low or medium $\mathrm{Gl}$ and boiled legumes low Gl. Wet processed foods tend to elicit higher GI than dry processed foods. This data will be of use when recommending foods to individuals who need to control their energy and carbohydrate intake.

Key words: glycaemic indices, glycaemic load, Sri Lankan food

\section{Introduction}

\section{Glycaemic index}

Glycaemic index (GI) categorises food items according to their potential to raise the postprandial blood glucose levels ${ }^{1}$. Carbohydrates in foods are digested at different rates releasing glucose into blood at different rates. Depending on the blood glucose raising potential of foods containing the same amount of digestible carbohydrate $(50 \mathrm{~g}$ or $25 \mathrm{~g}$ when portion size is too large to be consumed) when compared to the rise with glucose or white bread, they are classified as having low $(\mathrm{Gl} \leq 55)$, medium $(56 \geq \mathrm{Gl} \leq 69)$ or high $(\mathrm{Gl} \geq 70) \mathrm{Gl}^{2}$. The $\mathrm{Gl}$ concept is applied to foods providing $15 \mathrm{~g}-20 \mathrm{~g}$ of glycaemic carbohydrates per portion or serving size $^{3}$. All digestible carbohydrates in the foods/diet that release glucose contribute to a transient increase in the blood glucose level which is reflected by the $\mathrm{Gl}$ of a particular food. Rate of the rise in blood glucose vary depending on many factors such as the amount of protein, lipid, dietary fibre, starch granule structure, entrapment of starch and method of processing of foods etc ${ }^{1,3}$.

\section{Glycaemic load}

Sometimes the portion given to determine $\mathrm{Gl}^{4,5}$ can exceed the normal serving size of a meal and vice versa. Glycaemic load (GL) concept (GI x weight of carbohydrates in one normal serving portion/100) was introduced to apply the GI concept to a normal serving size of a meal ${ }^{3}$ which is categorized as high $(\geq 20)$, medium (11-19) and low $(\leq 10)$. Thus some foods that give high $\mathrm{Gl}$, when taken in normal portion sizes would give rise to a lower glycaemic response. Thus it is more practical to calculate the GL using the $\mathrm{Gl}$ rather than using only $\mathrm{Gl}$ to guide the food choice.

\section{Glycaemic index and glycaemic load in disease prevention}

The mortality due to non-communicable diseases in Sri Lanka is around $83 \%$ which includes 34\% cardiovascular diseases, $9 \%$ diabetes etc. and according to International Diabetes Federation the diabetes prevalence in adults is $8.7 \% \%^{6,7}$. Thus, dietary interventions and correct dietary choices together with

\footnotetext{
${ }^{1}$ Faculty of Medical Sciences University of Sri Jayewardenepura, Sri Lanka.
} 
pharmacological intervention are very important in preventing or controlling DM and associated complications. Many epidemiological studies have shown that frequent consumption of low $\mathrm{Gl}$ foods decreases the risk factors for diabetes (Type 2) and in addition cardiovascular diseases, obesity and cancers ${ }^{3}$. GI values are primarily used to guide selection of foods for diabetic patients but is also beneficial for healthy individuals.

\section{Glycaemic indices of some commonly consumed starchy foods}

\section{Rice}

The GI, GL and GL of a normal portion size of some rice varieties available in the market, mixed rice meals and milk rice are given in Table 1 . When considering commonly available rice, the major contributor to carbohydrate and energy in a Sri Lankan diet, raw (kekulu) rice irrespective of the variety (red raw, white raw, locally available red or white basmati) produced high glycaemic response and high $\mathrm{Gl}$ when given with minimum accompaniments (kirihodi or coconut sambol/),9,10.

The glycaemic load (GL) was in the high range $(>20)$ in the portion given to determine the GI in all rice varieties with minimum accompaniments (kirihodi or sambol) and this portion was considered as adequate by participants except for red basmati which contained more fibre. Thus, the glycaemic load (GL) of red basmati for an actual edible portion would be lower when compared to the white basmati variety and the local red variety would be a better choice (Figure 1).

Table 1. Glycaemic indices, glycaemic loads of only rice, rice mixed meals and milk rice

\begin{tabular}{|c|c|c|c|}
\hline Food/meal (accompaniment) & GI & $\begin{array}{c}\text { GL (portion } \\
\text { given for GI } \\
\text { determination) }\end{array}$ & $\begin{array}{c}G L \\
\text { (for edible } \\
\text { portion) }\end{array}$ \\
\hline \multicolumn{4}{|l|}{ Rice } \\
\hline Red raw (kirihodi) & $80 \mathrm{H}$ & 40 & 40 \\
\hline White raw (sambol) & $81 \mathrm{H}$ & 40 & $<40$ \\
\hline Red basmati (raw-local) (sambol) & $73 \mathrm{H}$ & 37 & 15 \\
\hline White (raw-Samurdhi) basmati (sambol) & $73 \mathrm{H}$ & 37 & $>37$ \\
\hline Keeri samba (raw) (sambol) & $66 \mathrm{M}$ & 33 & 33 \\
\hline Parboiled nadu (sambol) & $40 \mathrm{~L}$ & 20 & 20 \\
\hline White basmati (raw-India) (sambol) & $54 \mathrm{~L}$ & 27 & 27 \\
\hline White basmati (raw-Pakistan) (sambol) & $64 \mathrm{M}$ & 32 & 32 \\
\hline \multicolumn{4}{|l|}{ Rice mixed meals } \\
\hline Red raw rice (gotukola+dhal+egg+kirihodi) & $47 \mathrm{~L}$ & 23 & 16 \\
\hline Red raw rice (gotukola+dhal+egg+kirihodi+kohila & & & \\
\hline tuber sambol) [more dietary fibre] & $43 \mathrm{~L}$ & 22 & 15 \\
\hline Red raw rice (gotukola+dhal+egg+kirihodi+pathola sambol) & $46 \mathrm{~L}$ & 23 & 15 \\
\hline \multicolumn{4}{|l|}{ Milk rice } \\
\hline White (raw) milk rice (onion sambol) & $72 \mathrm{H}$ & 37 & 25 \\
\hline Red basmati milk rice (onion sambol) & $70 \mathrm{H}$ & 36 & 09 \\
\hline \multicolumn{4}{|l|}{ Green gram milk rice 1 (green gram: rice 1:3) } \\
\hline (onion sambol) & $65 \mathrm{M}$ & 33 & 22 \\
\hline Green gram milk rice 2 (green gram: rice 2:1) & & & \\
\hline (onion sambol) & $55 \mathrm{~L}$ & 29 & 08 \\
\hline
\end{tabular}

$\mathrm{H}$ - high $\mathrm{Gl} ; \mathrm{M}$ - medium $\mathrm{Gl} ; \mathrm{L}$ - low GI 
Compared to local basmati the GI of two imported white basmati varieties (Table 1) available in the market elicited low and medium $\mathrm{Gl}(\mathrm{Gl}=54 \mathrm{Gl}=64)^{11}$. Raw samba (kekulu keeri samba) produced a medium GI (66) and high GL. Thus among the local raw rice varieties a better metabolic response was obtained with samba rice $^{8}$. The naturally occurring dietary fibre in whole grains is not adequate to affect the glycaemic response and thus when given alone or with minimum accompaniments the $\mathrm{Gl}$ of any newly improved raw (kekulu) rice variety would be high or medium. Comparatively, many traditional raw rice varieties elicit medium or low $\mathrm{Gl}^{12}$.

Parboiled (nadu) rice elicited the lowest GI (low GI). A lower peaking (Figure 1) was seen even when given with only coconut samboll ${ }^{8}$. Likewise, when traditional rice varieties are parboiled the GI was low due to high moisture and fibre ${ }^{13}$. These indicate the suitability of any parboiled variety in the dietary regime of individuals with chronic NCDs or any individual.

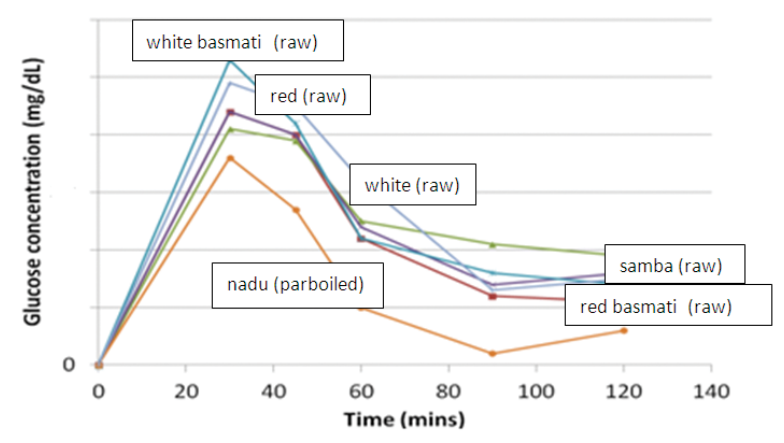

Figure 1. Glycaemic responses of different rice varieties.

When rice is consumed with many different curries the GI decreased significantly (39\%) compared to raw red rice (kirihodi) only meal and further the mixed meal was categorized as low GI (Table 1). Glycaemic load and the glucose peak also reduced compared to the rice given only with kirihodi ${ }^{9}$. GL of a normal portion was also less as two thirds of a portion was adequate due to addition of other accompaniments (Figure 2). This highlighted the importance of other accompaniments to a starchy base when attempting to control the glycaemic response. Accompaniments provide dietary fibre and proteins which help reduce glycaemic response. Rice mixed meal had the most desirable GL indicating the suitability of mixed meals in controlling the glycaemic response. However, the quantity of rice (starchy base) has to be taken into account when consuming as a large portion of rice will negate the beneficial effect of the meal.

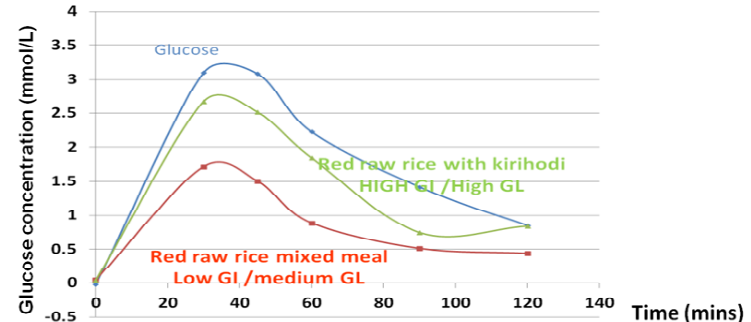

Figure 2. Glycaemic responses of rice only and mixed rice meal.

Increased addition of vegetables containing high dietary fibre (same mixed meal as above with additional portion of kohila sambol) contributed to lowering the $\mathrm{GI}$ to a certain extent (Table 1). However, beyond $16 \mathrm{~g}$ dietary fibre/portion failed to elicit a significant effect on the $\mathrm{Gl}^{14}$. Milk rice made with white raw and red basmati elicited high $\mathrm{GI}(72 \& 70)$ which reduced when green gram was incorporated in to milk rice (Gl-65). Further decrease in the $\mathrm{Gl}$ with increasing content of green gram incorporated in to the milk rice (Gl-55) was observed. This clearly indicated the suitability of milk rice made with green gram over milk rice without green gram in controlling the glycaemic response. Green gram milk rice had more protein and less fat compared to milk rice made without green gram irrespective of the rice variety. GL for an edible portion also decreases as green gram contributes protein and dietary fibre to a portion thus decreasing the carbohydrate load $^{10}$.

\section{Bread}

White as well as brown bread elicited high GI and constituted a high GL. However, the actual portion size that a person could consume contained a less GL in both white and brown bread (medium GL) when compared to the portion given to determine the GI. Even though brown bread eaten alone elicited a high GI when consumed with a dhal curry produced a medium GI (Table 2) and the metabolic response (lower peak eliciting lower insulin response) to the same carbohydrate load was better in the mixed meal compared to bread only (Figure 3$)^{15}$.

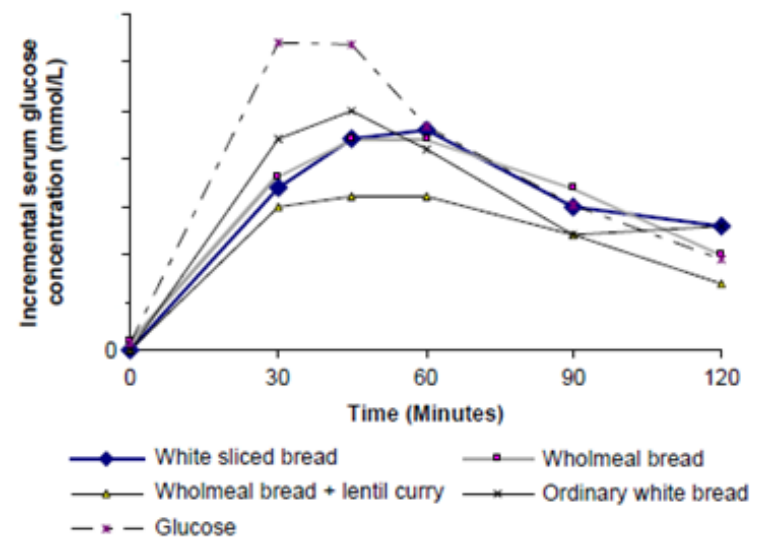

Figure 3. Glycaemic responses to bread in comparison to glucose (reproduced from 15). 
Table 2. GI and GL of bread and other starchy foods

\begin{tabular}{lccc}
\hline Food/meal & $G I$ & $\begin{array}{c}G L \text { (portion } \\
\text { given for GI } \\
\text { determination) }\end{array}$ & $\begin{array}{c}G L \\
\text { (for edible } \\
\text { portion) }\end{array}$ \\
\hline Bread & & & \\
White sliced bread & $77 \mathrm{H}$ & 39 & 20 (4 slices) \\
White bread (normal) & $80 \mathrm{H}$ & 40 & 20 (4 slices) \\
Brown bread & $77 \mathrm{H}$ & 39 & 16 (3 slices) \\
Brown bread+lentil curry & $61 \mathrm{M}$ & 31 & 19 (3 slices/ \\
& & & $100 \mathrm{~g}$ curry)
\end{tabular}

\section{Cereal based foods}

Hoppers (rice)+lunumiris

$\begin{array}{ccc}90 \mathrm{H} & 45 & >45 \\ 54 \mathrm{~L} & 27 & 27 \\ 52 \mathrm{~L} & 26 & 26 \\ 50 \mathrm{~L} & 25 & 25 \\ 52 \mathrm{~L} & 26 & <26 \\ 59 \mathrm{M} & 30 & <30 \\ 43 \mathrm{~L} & 21 & 21\end{array}$

String-hoppers (rice)+pol sambol +egg+kirihodi

$\begin{array}{lll}79 \mathrm{H} & 40 & 26\end{array}$

String-hoppers (wheat)+pol sambol+egg+kirihodi

$72 \mathrm{H}$

36

24

Pittu (rice flour 1:C1)+lunumiris

$76 \mathrm{H}$

40

40

Pittu (wheat flour 1:C1)+lunumiris

$75 \mathrm{H}$

37.5

37.5

Pittu (kurakkan 1:C1)+lunumiris

$64 \mathrm{M}$

32

$<20$

\section{Legumes}

Cowpea

Chickpea

Mung beans
$22 \mathrm{~L}$

$34 \mathrm{~L}$

$47 \mathrm{~L}$
6

9

11
6

9

11

$\mathrm{C}$ - coconut; $\mathrm{H}$ - high $\mathrm{Gl} ; \mathrm{M}$ - medium $\mathrm{Gl} ; \mathrm{L}$ - low $\mathrm{Gl}$ 
Thus bread, when consumed with other accompaniments rather than with spreads/jam alone would give rise to a lower glycaemic response and hence a lower $\mathrm{Gl}$ due to the reduction of the portion size of bread due to other food accompaniments which will add other nutrients (protein and fibre) and contribute to reduce the GI. Thus, consumption of bread with vegetables, legumes or fish /meat, sambol etc. should be promoted. This is also a good food habit to inculcate in children from a young age as bread has become an essential part of our diet.

\section{Hoppers}

Both the $\mathrm{Gl}$ and $\mathrm{GL}$ of the hoppers made with rice flour were high and the portion given to determine the GI was considered as not adequate by majority of participants. Thus, consuming hoppers would contribute to a high GL and is not a suitable food for daily or frequent consumption if the aim is to lower the glucose/energy intake. However, eating hoppers with other accompaniments (fish / chicken/ soy / egg etc.) (not only with onion sambol) will help cut down the hopper portion size and reduce the GL and blood glucose peak $^{16}$. The high $\mathrm{Gl}$ is due to complete destruction of the starch granules in flour during the preliminary processing (overnight soaking) which makes starch more available for enzymic hydrolysis leading to a high glycaemic response ${ }^{17}$.

\section{Roti}

Roti made in the typical Sri Lankan way by incorporating coconut scrapings and irrespective of the flour used in the preparation, elicited low or medium GI although the glycaemic load was high. Roti made with kurakkan flour contained the lowest GL due to the high dietary fibre which again decrease the digestible carbohydrate in a portion and contributes to satiety ${ }^{16}$. When roti was made using kithul flour a lower GI was observed ${ }^{18}$. Compared to hoppers, roti would be a healthier option for frequent consumption with a lower energy contribution. Even with a high glycaemic load, the blood glucose peaking following consumption of roti was low compared to hoppers due to less gelatinization of the starch (dry processing $)^{17}$.

\section{String-hoppers}

Irrespective of flour used in preparation (wheat or red rice) and when consumed with as many accompaniments as with a red raw rice mixed meal (low GI) except for the dhal curry (replaced with kirihodi), string hoppers elicited a high $\mathrm{GI} \mathrm{GL}^{8}$ (Table 2: Figure 4) similar to brown bread ${ }^{15}$. Addition of a dhal curry instead of kirihodi may be more advisable as this could lead to a reduction in the $\mathrm{Gl}$ and $\mathrm{GL}$ as dhal contributes to dietary fibre and protein in the mixed meal and in addition contain slow release carbohydrate. Compared to string-hoppers, rice mixed meal produced a better metabolic response. Thus, frequent consumption of large portions of string-hoppers should be avoided if the aim is to reduce the glycaemic response.

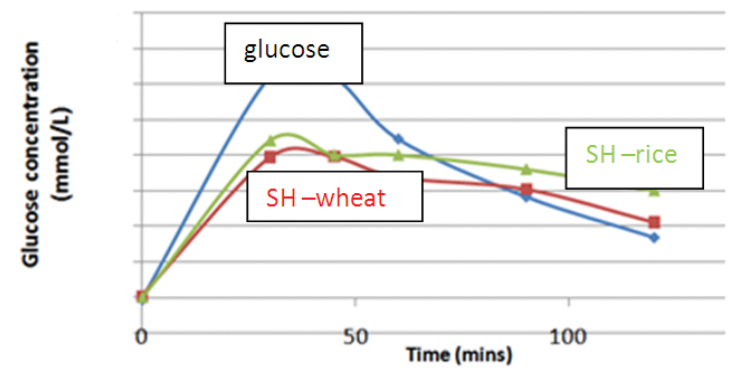

Figure 4. Glycaemic responses to string-hopper meals made with wheat and rice flour against glucose.

\section{Pittu}

Pittu when prepared using wheat or rice flour elicited high $\mathrm{Gl}$ and had a high GL even for a normal portion (Table 2$)^{16}$. The wet processing contributes to disintegration of the starch granules making them easily available for digestion ${ }^{17}$. However, when kurakkan was used in the preparation, both GI and the $\mathrm{GL}$ decreased (Figure 5) due to the higher fibre content ${ }^{16}$.

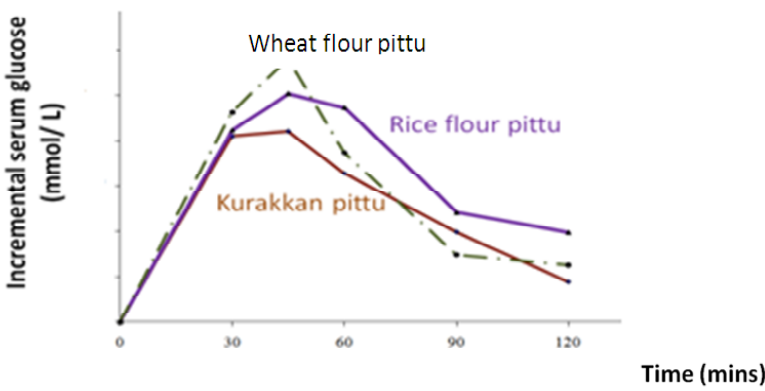

Figure 5. Glycaemic responses to pittu made with wheat, rice and kurakkan flour.

Kurakkan pittu elicited a medium $\mathrm{Gl}$ value and the volunteers who consumed the portion $(50 \mathrm{~g}$ digestible carbohydrate) indicated that the portion size was too large to be consumed ${ }^{16}$. Thus in real-life setting the glycaemic load given by fibre rich kurakkan preparations would be lower and beneficial in persons aiming to conrtrol blood sugar levels. 


\section{Legumes}

In contrast to some cereal foods, boiled legumes, chickpea, cowpea and mung beans when consumed as a breakfast meal elicited low GI (Figure 6) and constituted a low or medium GL. The incremental increase in blood glucose was low giving rise to lower insulin demand. The high dietary fibre and protein in these legumes have contributed to lower the $\mathrm{Gl}^{16}$. Even though legumes are a good source of carbohydrate, the nature of the carbohydrate is such, they are digested slowly (lente carbohydrates) ${ }^{17}$. Thus, the slowrelease carbohydrates, high protein and dietary fibre contribute to decrease the glucose absorption giving rise to a low $\mathrm{Gl}$ and low GL and is highly suitable for maintaining low blood glucose levels.

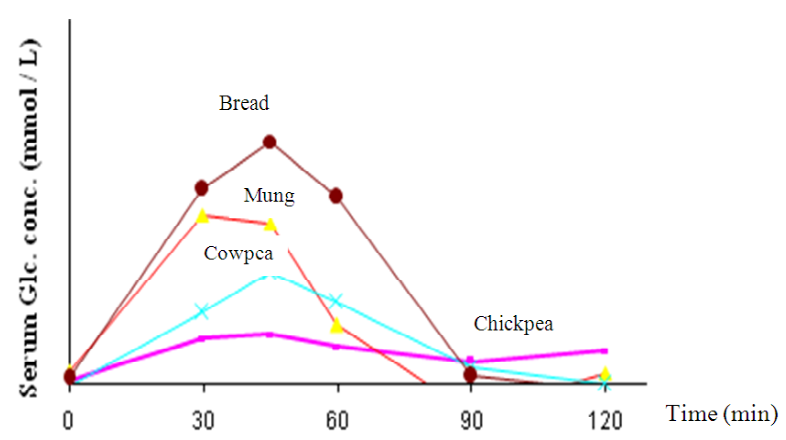

Figure 6. Glycaemic responses to boiled legumes compared to bread.

\section{Conclusions}

Consumption of any rice variety as a mixed meal with as many accompaniments that contribute dietary fibre (vegetables, green leaves, legumes) and adjusting the rice portion to suit individual energy requirement will help control the glycaemic response and insulin response. Among rice, parboiled rice is the healthiest choice due to high moisture in cooked rice and fibre which decrease the carbohydrate load. A balanced rice meal irrespective of the variety would induce a lower glycaemic response. Bread when consumed with accompaniments will elicit lower $\mathrm{Gl}$ and $\mathrm{GL}$ than when consuming with spreads/jam or alone. Wet processed foods such as pittu, rice, string hoppers (steaming) tended to elicit higher GI compared to dry processed food such as roti due to higher starch gelatinization. Legumes, rich in protein and fibre elicit low GI ad GL due to slow release (lente) carbohydrates and are beneficial in controlling the glycaemic response. The glycaemic response of high $\mathrm{Gl}$ foods can be lowered by including low/medium GI foods in the meal (e.g.: high $\mathrm{Gl}$ rice/bread/string hoppers with curries prepared with legumes such as lentil/chickpea curry).
Note: The data given above have been generated in the Department of Biochemistry, Faculty of Medial Sciences, University of Sri Jayewardenepura, Sri Lanka. For determination of the $\mathrm{Gl}$ of each of these the ingredient ratios mentioned in the table were used ${ }^{19}$. However, a change in the ingredient com-position may also be used to manipulate $\mathrm{Gl}$ of a particular food to a small extent.

\section{Acknowledgements}

All volunteers who particiapted in the studies, the researchers who tirelessly contributed to generate the above data and funding by NRC and NSF Sri Lanka, IFS and IPICS Sweden, University of Sri Jayewardenepura, Sri Lanka are gratefully acknowledged.

\section{References}

1. Jenkins DJ, Wolever TM, Taylor RH, et al. Glycemic index of foods: a physiological basis for carbohydrate exchange. American Journal of Clinical Nutrition 1981; 34:(3) 362-6.

2. Beals KA. The glycaemic index: research meets reality ${ }^{*} A$ special publication. 2005.Denver, USA: United States Potato Board.

3. Tema Nord 2005-589; Glycaemic index; From research to Nutrition recommendations? Nordic Council of Ministers, Copenhagen 2005.

4. FAO/WHO. Carbohydrates in human nutrition. Report of a joint expert consultation. Food and Nutrition Paper 66. 1998. Rome: FAO.

5. Brouns F, Bjorck I, Frayn KN et al. Glycemic index methodology. Nutrition Research Reviews 2005: 18: 145-71.

6. World Health Organization, (2018) Non -communicable Diseases Country Profile [online] Available at https:// www.who.int/nmh/countries/lka_en.pdf (accessed: 10 February 2020].

7. https://idf.org/our-network/regions-members/south-eastasia/members/98-sri-lanka.html (accessed: 2 April 2020).

8. Nisanka US, Ekanayake S. Rice variety and processing: contribution to glycaemic response. Ceylon Medical Journal 2016; 61: 159-62.

9. Hettiaratchi UPK, Ekanayake S, Welihinda J. Do Sri Lankan meals help decrease blood glucose response? Ceylon Medical Journal 2009; 54: 39-43.

10. Wathupola A, Ekanayake S, Welihinda J. Glycaemic responses and glycaemic indices of rice and milk rice made with sudu kekulu and red basmathi rice. Annual Scientific Sessions of the Nutrition Society of Sri Lanka, 2-3 February 2013.

11. Gunathilaka MDTL, Ekanayake S. Effect of different cooking methods on glycaemic index (GI) of Indian and Pakistani basmati rice varieties Ceylon Medical Journal 2015; 60: 57-61. 
12. Bhagya KADL, Ekanayake S. Assessment of glycemic responses of five Sri Lankan traditional (Oryza sativa) rice varieties. International conference on Agriculture and Food Security 2019. Sri Lanka. August 2019.

13. Thennakoon TAPU, Ekanayake S. Sri Lankan traditional rice: Does parboiling contributes to lower the carbohydrate load in an edible portion? International conference on Agriculture and Food Security 2019. Sri Lanka. August 2019.

14. Hettiaratchi UPK, Ekanayake S, Welihinda J. Sri Lankan rice mixed meals: Effect on glycaemic index and contribution to daily dietary fibre requirement. Malaysian Journal of Nutrition 2011; 17: 97-104.

15. Hettiaratchi UPK, Ekanayake S, Welihinda J. Glycaemic indices of 03 Sri Lankan wheat bread varieties and a breadlentil meal. International Journal of Food Sciences and Nutrition 2009; 60(S4): 21-30.
16. Widanagamage R, Ekanayake, S, Welihinda J. Carbohydrate rich foods: glycaemic indices and correlation with macronutrients. International Journal of Food Science and Nutrition 2009; 60(S4): 215-23.

17. Widanagamage R, Ekanayake S, and Welihinda J. Effect of extent of gelatinization of starch on the glycaemic responses of carbohydrate rich breakfast meals. Malaysian Journal of Nutrition 2013; 19: 233-42.

18. Senavirathna RMISK, Ekanayake S, Jansz ER, Welihinda J. Traditional and novel foods from indigenous flours: nutritional quality, glycaemic response and potential use in food industry. Starch/Starke 2016; 68:(9-10) 999-1007.

19. The GIs of typical Sri Lankan foods are available at http:// www.nrc.gov.lk/SAG/index.html. 